\title{
Novel Endoscopic Therapy for Gastric Varices Using Direct Forward-Viewing Endoscopic Ultrasonography
}

Keiji Yokoyama Takashi Miyayama Yotaro Uchida Hiromi Fukuda

Ryo Yamauchi Naoaki Tsuchiya Kaoru Umeda Kazuhide Takata

Takashi Tanaka Shinjiro Inomata Daisuke Morihara

Yasuaki Takeyama Satoshi Shakado Shotaro Sakisaka Fumihito Hirai

Department of Gastroenterology and Medicine, Fukuoka University Faculty of Medicine,

Fukuoka, Japan

\section{Keywords}

Endoscopic treatment - Endoscopic ultrasonography · Liver cirrhosis · Portal

hypertension - Gastric varices

\begin{abstract}
Gastric varices (GV) carry a high risk of massive hemorrhage because of potential rupture. To reduce the risk associated with GV, patients need to undergo hemostatic and preventive treatment. The objective of this retrospective study was to evaluate the usefulness of a new method, direct forward-viewing endoscopic ultrasonography (DFV-EUS) for the treatment of GV. We performed endoscopic injection sclerotherapy with histoacryl (EISHA) using DFV-EUS for GV in four patients. The paracentesis success rate was $75 \%$ (3/4). DFV-EUS has a significant advantage for the treatment of GV in that it can show physicians endoscopic and ultrasound views in real time during the delivery of the sclerosant into the GV. However, the proper use of the ultrasound view must be elucidated through further
\end{abstract}

\begin{tabular}{ll}
\hline & Keiji Yokoyama \\
Department of Gastroenterology and Medicine & Fukuoka University Faculty of Medicine \\
$7-45-1$ Nanakuma, Jonan-ku, Fukuoka-shi, Fukuoka 814-0180 (Japan) \\
yokotin@fukuoka-u.ac.jp
\end{tabular}




\section{Case Reports in Gastroenterology}

\begin{tabular}{l|l}
\hline Case Rep Gastroenterol 2021;15:28-34 \\
\hline DOI: 10.1159/000510132 & $\begin{array}{l}\text { @ 2021 The Author(s). Published by S. Karger AG, Basel } \\
\text { www.karger.com/crg }\end{array}$ \\
\hline
\end{tabular}

Yokoyama et al.: Novel Endoscopic Therapy for Gastric Varices Using Direct ForwardViewing Endoscopic Ultrasonography

research for safer and more effective therapy. In the presence of distance between the mucosal surface and vascular lumen or when the blood flow site requires puncture as an additional treatment, DFV-EUS might be a good candidate for the treatment of GV. Altogether, EIS-HA with DFV-EUS might be a new therapeutic option for patients with GV.

(C) 2021 The Author(s)

Published by S. Karger AG, Basel

\section{Introduction}

Gastric varices (GV) occur in approximately $20 \%$ of patients with portal hypertension and require hemostatic and preventive treatments due to GV rupture-associated hemorrhaging or liver failure [1]. In our department, endoscopic injection sclerotherapy with N-butyl-2-cyanoacrylate (histoacryl) (EIS-HA) is performed for GV cases with bleeding and difficult cases in which balloon-occluded retrograde transvenous obliteration (BRTO) is contraindicated.

It has been proven that endoscopic ultrasonography (EUS) is useful for accurately evaluating the treatment in varices [2-6]. Moreover, the use of EUS for actual treatment has also been reported [7-13]. However, direct forward-viewing EUS (DFV-EUS) for treating GV is less known than oblique viewing therapy.

This report describes the usefulness of DFV-EUS as a new method for treating GV.

\section{Case Report}

\section{Methods}

The present study was a retrospective analysis using past medical information. This study protocol was approved by the Ethics Committee of Fukuoka University Hospital (approval No. H19-10-001).

Between January 2016 and June 2019 in the data collection period, four patients diagnosed with GV (F3, RC0) had unacceptable hemodynamics to undergo BRTO in our hospital. Therefore, we performed EIS-HA using DFV-EUS (scanning angle $90^{\circ}$, viewing angle $120^{\circ}$; TGF-UC260J, Olympus). The concentration of histacryl used in EIS-HA was $75 \%$ in all four cases. EIS-HA with DFV-EUS was able to puncture needle in real time while simultaneously observing the endoscopic and ultrasonic fields. When it was difficult to puncture, it was possible to immediately switch to conventional endoscopic treatment and complete the treatment. We analyzed the therapeutic effect and safety of these 4 cases in this study. The shape of the EUS tip is shown in Fig. 1a and the treatment schema is shown in Fig. 1b.

This study was conducted in compliance with the Declaration of Helsinki and the Ethical Guidelines for Medical Research of the Ministry of Health, Labor and Welfare. Information obtained in this study was kept strictly anonymous. This study was a retrospective study using past medical information, and it was impossible to obtain the consent of this study from the target patients in advance. Therefore, we announced the outline of this clinical study on our website.

\section{Karger'=}




\section{Case Reports in Gastroenterology}

\begin{tabular}{l|l}
\hline Case Rep Gastroenterol 2021;15:28-34 \\
\hline DOI: 10.1159/000510132 & $\begin{array}{l}\text { ( ) 2021 The Author(s). Published by S. Karger AG, Basel } \\
\text { www.karger.com/crg }\end{array}$ \\
\hline
\end{tabular}

Yokoyama et al.: Novel Endoscopic Therapy for Gastric Varices Using Direct ForwardViewing Endoscopic Ultrasonography

\section{Results}

The background information and the summary of the four patients' treatment outcomes are shown in Table 1. Case 1 with isolated GV1 (IGV1) could not undergo BRTO because of unacceptable hemodynamics, so we performed EIS-HA using the conventional endoscopic view. However, the treatment was unsuccessful because there was distance between the mucosal surface and vascular lumen. Therefore, we performed EIS-HA using DFV-EUS and we successfully punctured and treated the GV with DFV-EUS (shown in Fig. 2a-c). We successfully punctured the GV in the endoscopic view using DFV-EUS in three of four cases (cases 1-3). As aforementioned, case 1 was a typical patient in whom we were able to successfully treat GV with DFV-EUS, although it was difficult to treat the patient with only the conventional endoscopic view. Comparative images before and after therapy for case 3 are shown in Fig. 3a-d. In case 4, however, securing the visual field under EUS was not easy. Therefore, the treatment was completed after changing the method to paracentesis under the visual field of only the conventional endoscopic view. All four cases had no complications and achieved a good therapeutic effect of EIS-HA for GV. The paracentesis success rate using DFV-EUS was 75\% (3/4) in this study.

\section{Discussion}

Evaluation of gastroesophageal varices using EUS has been conducted since the 1980s [2], and various considerations have been made. Iwase et al. [3] reported that there was a significant positive correlation between the blood vessel diameter and blood flow velocity with the average diameter being $10.2 \pm 2.6 \mathrm{~mm}$ and the average velocity being $5.3 \pm 3.7 \mathrm{~cm} / \mathrm{s}$ in GV. Ramond et al. [4] reported that there was a high risk of developing varices within 6 months in patients in whom blood flow was observed on Doppler EUS after endoscopic therapy and that some additional treatment should be considered in such patients.

Other studies have reported intermittently on the usefulness of EUS as the method of evaluation, early recurrence, and rebleeding of blockages in GV after treatment $[5,6]$. In a pilot study of five patients in whom cyanoacrylate was injected in real time under EUS guidance using oblique viewing (indirect forward-viewing) model unlike the model used in the present study, successful treatment outcome was achieved by using only EUS and fluoroscopy in cases complicated by hemorrhaging wherein it is difficult to secure the visual field of the endoscope [7]. Recently, coil embolization under EUS guidance has been reported [8-10], and various methods have been devised to improve treatment results $[11,12]$. Previous report had compared DFV-EUS and oblique-viewing EUS for drainage of pancreatic fluid collections [13]; however, this is the first report to use DFV-EUS for the treatment of GV.

This DFV-EUS method has a great advantage for treating GV in that it can show both the endoscopic and ultrasound views in real time during treatment. However, we noted two limitations of this method. First, the endoscopic view is limited because the stomach lumen is filled with degassed water. Second, it is difficult to ensure stabilization of the entire revolver needle in the view of the ultrasound field. Some authors have warned against the use of unnecessarily 


\section{Case Reports in Gastroenterology}

Case Rep Gastroenterol 2021;15:28-34

(c) 2021 The Author(s). Published by S. Karger AG, Basel www.karger.com/crg

Yokoyama et al.: Novel Endoscopic Therapy for Gastric Varices Using Direct ForwardViewing Endoscopic Ultrasonography

complicated procedures [14]. Thus, proper use of the ultrasound view needs to be considered in order to ensure safer and more effective therapy. From our view of experience, we recommend that if treatment with the conventional endoscopic view is possible, then the conventional approach should be used. However, when there is distance between the mucosal surface and vascular lumen or when the blood flow site requires puncture as an additional treatment, DFV-EUS method could serve as a good option.

In conclusion, EIS-HA with DFV-EUS may be one of the new therapeutic options for treating GV which is more difficult to treat only with the conventional endoscopic view.

\section{Acknowledgement}

We would like to thank Editage (www.editage.com) for English language editing. We also would like to express our gratitude to Eri Yamauchi, Motoko Kawashima, Waki Nagashima, Yuki Nozaki, Atsuko Ishibashi, Nao Kodama, Rina Akahoshi, Chihiro Tanaka, Akiko Tanaka, and Tomoko Nagaura for invaluable support.

\section{Statement of Ethics}

These patients have given written informed consent to publish the case, including publication of images.

\section{Conflict of Interest Statement}

The authors have no conflicts of interest to declare.

\section{Funding Sources}

The authors have no sponsors or any funding sources to report.

\section{Author Contributions}

All authors participated in data collection and Keiji Yokoyama contributed to writing the manuscript. All authors read and approved the final manuscript. 


\section{Case Reports in Gastroenterology}

(C) 2021 The Author(s). Published by S. Karger AG, Basel www.karger.com/crg

Yokoyama et al.: Novel Endoscopic Therapy for Gastric Varices Using Direct ForwardViewing Endoscopic Ultrasonography

\section{References}

1 Consolo P, Luigiano C, Giacobbe G, Scaffidi MG, Pellicano R, Familiari L. Cyanoacrylate glue in the management of gastric varices. Minerva Med. 2009 Feb;100(1):115-21.

2 McCormack T, Martin T, Smallwood RH, Robinson P, Walton L, Johnson AG. Doppler ultrasound probe for assessment of blood-flow in oesophageal varices. Lancet. 1983 Mar;1(8326 Pt 1):677-8.

3 Iwase H, Suga S, Morise K, Kuroiwa A, Yamaguchi T, Horiuchi Y. Color Doppler endoscopic ultrasonography for the evaluation of gastric varices and endoscopic obliteration with cyanoacrylate glue. Gastrointest Endosc. 1995 Feb;41(2):150-4.

4 Ramond MJ, Valla D, Mosnier JF, Degott C, Bernuau J, Rueff B, et al. Successful endoscopic obturation of gastric varices with butyl cyanoacrylate. Hepatology. 1989 Oct;10(4):488-93.

5 Hino S, Kakutani H, Ikeda K, Yasue H, Kitamura Y, Sumiyama K, et al. Hemodynamic analysis of esophageal varices using color Doppler endoscopic ultrasonography to predict recurrence after endoscopic treatment. Endoscopy. 2001 Oct;33(10):869-72.

6 Kakutani H, Hino S, Ikeda K, Mashiko T, Sumiyama K, Uchiyama Y, et al. Use of the curved linear-array echo endoscope to identify gastrorenal shunts in patients with gastric fundal varices. Endoscopy. 2004 Aug;36(8):710-4.

7 Romero-Castro R, Pellicer-Bautista FJ, Jimenez-Saenz M, Marcos-Sanchez F, Caunedo-Alvarez A, OrtizMoyano C, et al. EUS-guided injection of cyanoacrylate in perforating feeding veins in gastric varices: results in 5 cases. Gastrointest Endosc. 2007 Aug;66(2):402-7.

8 Romero-Castro R, Ellrichmann M, Ortiz-Moyano C, Subtil-Inigo JC, Junquera-Florez F, Gornals JB, et al. EUSguided coil versus cyanoacrylate therapy for the treatment of gastric varices: a multicenter study (with videos). Gastrointest Endosc. 2013 Nov;78(5):711-21.

9 Bhat YM, Weilert F, Fredrick RT, Kane SD, Shah JN, Hamerski CM, et al. EUS-guided treatment of gastric fundal varices with combined injection of coils and cyanoacrylate glue: a large U.S. experience over 6 years (with video). Gastrointest Endosc. 2016 Jun;83(6):1164-72.

10 Khoury T, Nadella D, Wiles A, Marshall C, Kumar M, Shapira G, et al. A review article on gastric varices with focus on the emerging role of endoscopic ultrasound-guided angiotherapy. Eur J Gastroenterol Hepatol. 2018 Dec;30(12):1411-5.

11 Wani ZA, Bhat RA, Bhadoria AS, Maiwall R, Choudhury A. Gastric varices: Classification, endoscopic and ultrasonographic management. J Res Med Sci. 2015 Dec;20(12):1200-7.

12 McCarty TR, Bazarbashi AN, Hathorn KE, Thompson CC, Ryou M. Combination therapy versus monotherapy for EUS-guided management of gastric varices: A systematic review and meta-analysis. Endosc Ultrasound. 2020 Jan-Feb;9(1):6-15.

13 Voermans RP, Ponchon T, Schumacher B, Fumex F, Bergman JJ, Larghi A, et al. Forward-viewing versus oblique-viewing echoendoscopes in transluminal drainage of pancreatic fluid collections: a multicenter, randomized, controlled trial. Gastrointest Endosc. 2011 Dec;74(6):1285-93.

14 Seewald S, Ang TL, Imazu H, Naga M, Omar S, Groth S, et al. A standardized injection technique and regimen ensures success and safety of N-butyl-2-cyanoacrylate injection for the treatment of gastric fundal varices (with videos). Gastrointest Endosc. 2008 Sep;68(3):447-54. 


\section{Case Reports in Gastroenterology}

Case Rep Gastroenterol 2021;15:28-34

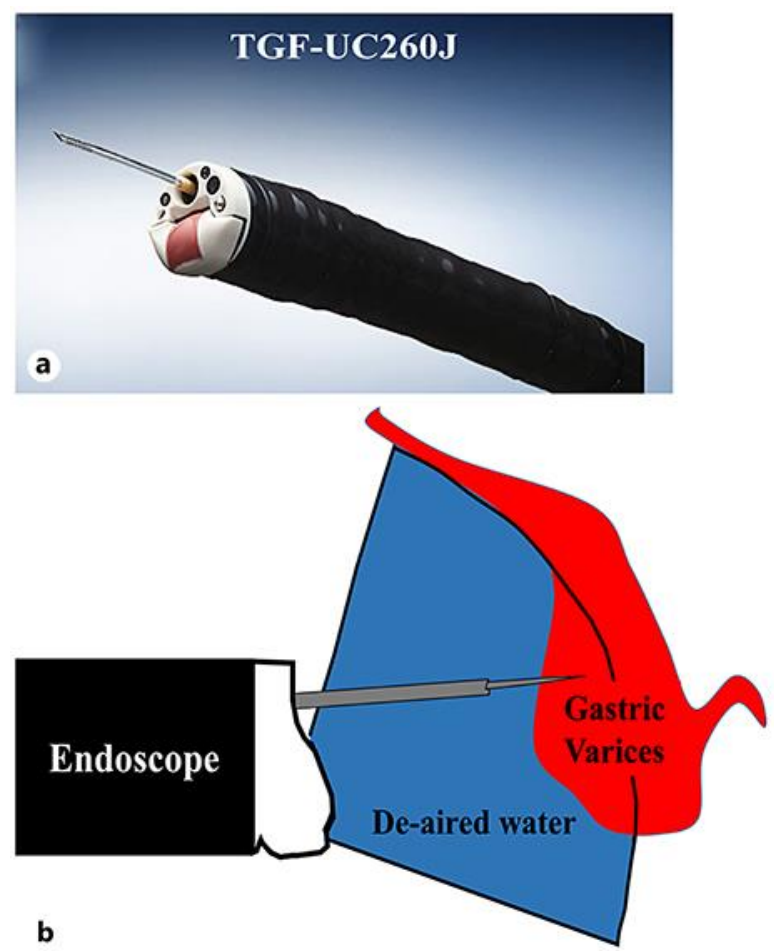

Fig. 1. a Shape of the direct forward-viewing endoscopic ultrasound tip (TGF-UC260J, Olympus). b The treatment schema of endoscopic injection sclerotherapy with histoacryl (EIS-HA) using direct forwardviewing endoscopic ultrasonography (scanning angle $90^{\circ}$, viewing angle $120^{\circ}$ ).
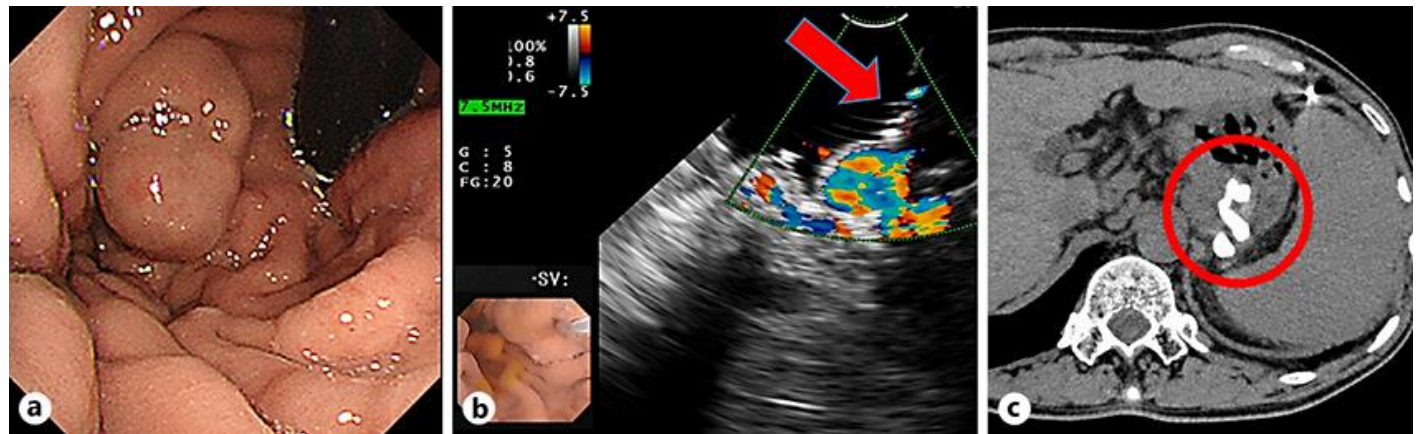

Fig. 2. a Endoscopic findings before treatment of case 1. b Endoscopic ultrasound findings during treatment of case 1 (the arrow shows the needle puncture). c Abdominal computed tomography findings after treatment of case 1 (the circle indicates the site of successful treatment). 


\section{Case Reports in Gastroenterology}

Case Rep Gastroenterol 2021;15:28-34

(C) 2021 The Author(s). Published by S. Karger AG, Basel www.karger.com/crg

Yokoyama et al.: Novel Endoscopic Therapy for Gastric Varices Using Direct Forward-

Viewing Endoscopic Ultrasonography

Case 3.

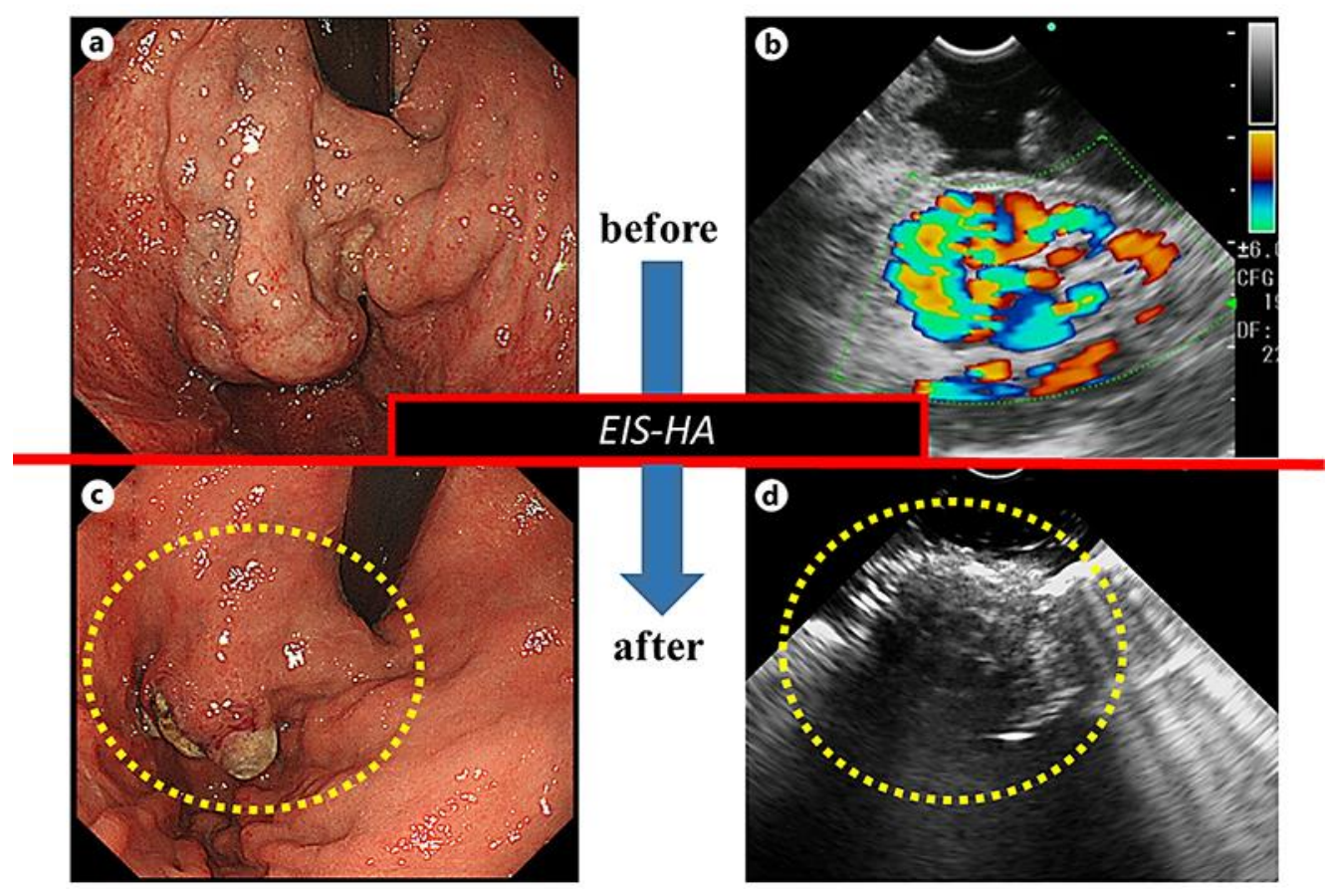

Fig. 3. a Endoscopic findings before treatment of case 3. b Endoscopic ultrasound findings before treatment of case 3. c Endoscopic findings after treatment of case 3 (the dotted circle indicates the site of successful treatment). $\mathbf{d}$ Endoscopic ultrasound findings after treatment of case 3 (the dotted circle indicates the site of successful treatment).

Table 1. Background information and summary of the four patients' treatment outcomes

\begin{tabular}{llllllll}
\hline Case & Age & Sex & Etiology & Location & Form, RC & Timing of treatment & Effect of treatment \\
\hline 1 & 59 & M & LC-B & Lg-cf & F3, RC0 & Prevention & Good \\
2 & 75 & M & LC-NBNC & Lg-f & F3, RC1 & Prevention & Good \\
3 & 63 & M & LC-Alcohol & Lg-cf & F3, RC1 & Prevention & Good \\
4 & 58 & M & LC-Alcohol & Lg-f & F3, RC0 & Prevention & Switch to conventional treatment \\
\hline
\end{tabular}

LC, liver cirrhosis; RC, red color sign. 